\title{
Incidência de Sclerotinia sclerotiorum em sementes de soja e sensibilidade dos testes de detecção
}

\author{
Luciane Henneberg(1), Edilaine Maurícia Gelinski Grabicoski(2), David de Souza Jaccoud-Filho(2) \\ e Maristela Panobianco(1)
}

\begin{abstract}
(1)Universidade Federal do Paraná, Departamento de Fitotecnia e Fitossanitarismo, Rua dos Funcionários, no 1.540, Juvevê, Caixa Postal 19061, CEP 80035-050 Curitiba, PR. E-mail: lucihenne@gmail.com, maristela@ufpr.br (2)Universidade Estadual de Ponta Grossa, Departamento de Fitotecnia e Fitossanidade, Campus de Uvaranas, Bloco F, Avenida Carlos Cavalcanti, no 4.748, Uvaranas, CEP 84030-900 Ponta Grossa, PR. E-mail: edilainegrabicoski@hotmail.com, dj1002@uepg.br
\end{abstract}

Resumo - O objetivo deste trabalho foi avaliar a eficiência dos métodos de detecção de Sclerotinia sclerotiorum em sementes de soja. Foram realizados experimentos durante três safras, tendo-se utilizado amostras de sementes de soja contaminadas artificial e naturalmente, com incidência conhecida da doença nas amostras e no campo. Os métodos de incubação utilizados foram: papel de filtro, rolo de papel e meio Neon-S. Observou-se aumento da detecção do patógeno nas sementes infectadas artificialmente, à proporção que aumentou a incidência na amostra. Os métodos podem não detectar o patógeno S. sclerotiorum em sementes de soja naturalmente contaminadas. Os níveis de incidência do patógeno em sementes de soja interferem na sensibilidade dos métodos de detecção, e não há relação entre a incidência no campo e na semente colhida.

Termos para indexação: meio Neon-S, método do papel de filtro, método do rolo de papel, mofo-branco.

\section{Incidence of Sclerotinia sclerotiorum on soybean seeds and sensitivity of detection tests}

\begin{abstract}
The objective of this work was to evaluate the efficiency of detection methods of Sclerotinia sclerotiorum on soybean seeds. Experiments were carried out during three crop years, using samples of soybean seeds artificially and naturally contaminated, with known pathogen incidence on samples and on the field. The incubation methods used were: filter paper, paper roll, and Neon-S medium. An increase in pathogen detection on artificially contaminated seeds was observed, as the incidence in the sample increased. The methods may not detect the pathogen S. sclerotiorum on naturally contaminated soybean seeds. The levels of pathogen incidence on soybean seeds interfere in the sensitivity of the detection methods, and there is no relationship between the incidence on the field and on the harvested seed.
\end{abstract}

Index terms: Neon-S medium, filter paper method, paper roll method, white mold.

\section{Introdução}

Sclerotinia sclerotiorum (Lib.) de Bary é um patógeno de importância mundial, por ocorrer tanto em regiões temperadas quanto subtropicais e tropicais, além de ser um fungo polífago, que infecta 408 espécies e 278 gêneros de plantas hospedeiras (Bolton et al., 2006). Epidemias causadas pelo patógeno, na cultura da soja, têm sido responsáveis pela diminuição da produção em vários países, com perdas que chegam a 100\%, em condições favoráveis (Saharan \& Mehta, 2007; Silva et al., 2008).

A doença causada por este fungo é conhecida como mofo-branco, e a sua disseminação ocorre principalmente pela semente (Yang et al., 1998). O fungo é de difícil erradicação após introduzido na área de cultivo. Assim, a detecção preventiva nas sementes constitui-se uma das medidas mais econômicas e importantes para se evitar a introdução da doença em novos locais e a sua disseminação em lavouras comerciais (Gomes et al., 2008).

Há diferentes métodos para a detecção do patógeno na semente de soja, entre os quais se destaca a incubação em substrato de papel ou método do papel de filtro ("blotter test"); em rolo de papel; e em meio agar-bromofenol Neon (Nasser et al., 1999; Machado, 2002; Peres et al., 2002; Taylor et al., 2006; Manual de análise sanitária de sementes, 2009).

A detecção de $S$. sclerotiorum pode depender do nível de infecção do patógeno na semente. Quando a semente é infectada artificialmente em laboratório, o fungo é facilmente detectado por testes de sanidade. 
No entanto, Henneberg et al. (2012), ao avaliar sementes de soja inoculadas com S. sclerotiorum, verificaram a formação de escleródios em poucos dias e que os métodos recomendados não foram eficientes para a detecção do patógeno em sementes comerciais provenientes de áreas infestadas. Resultado semelhante foi obtido por Koch (1998), que observou a detecção do patógeno em apenas $35,1 \%$ das amostras de sementes de feijão, provenientes de campos infestados. Portanto, há a necessidade de determinar a capacidade dos métodos em detectar $S$. sclerotiorum em sementes naturalmente contaminadas, que serão comercializadas pelas regiões produtoras de soja do país.

O objetivo deste trabalho foi avaliar a eficiência dos métodos de detecção de Sclerotinia sclerotiorum em sementes de soja.

\section{Material e Métodos}

O trabalho foi realizado no Laboratório de Patologia de Sementes, da Universidade Estadual de Ponta Grossa, PR. Foram comparados cinco métodos: método do papel de filtro ("blotter test"), com três temperaturas diferentes $\left(7,14\right.$ e $\left.20^{\circ} \mathrm{C}\right)$; rolo de papel; e meio agar-bromofenol (Neon-S), tendo-se utilizado amostras de sementes de soja com diferentes níveis de incidência de $S$. sclerotiorum.

Para a obtenção das amostras de sementes com diferentes níveis de incidência, foram conduzidos experimentos em três safras agrícolas, na região dos Campos Gerais, PR, entre 2008 e 2009. Foram considerados como níveis de incidência: amostras de semente com incidência conhecida da doença, obtida da contaminação artificial das sementes; e amostras obtidas a partir de cultivos com incidência conhecida da doença, no campo, e de sementes colhidas diretamente de plantas de soja doentes.

As amostras de sementes de soja contaminadas foram obtidas da cultivar CD 206, safra 2008/2009, provenientes de área sem histórico de ocorrência de S. sclerotiorum, localizada na Fazenda Escola, da Universidade Estadual de Ponta Grossa, PR. As sementes foram contaminadas artificialmente por meio do método de contato direto, para obtenção de cinco amostras de sementes com incidências conhecidas da doença.

O método de contato direto consistiu na incubação da semente sobre a cultura do patógeno. Para a obtenção da cultura de $S$. sclerotiorum, utilizaram-se escleródios do fungo $S$. sclerotiorum da coleção do Laboratório de Fitopatologia, da Universidade Federal de Uberlândia, MG, desinfestados superficialmente com solução de hipoclorito de sódio $0,5 \%$ por 5 min e lavados em água destilada esterilizada. Em seguida, os escleródios desinfestados foram transferidos para placas de Petri (90 mm) - um escleródio por placa - contendo meio batata-dextrose-agar (BDA), tendo sido incubados em BOD, a $20^{\circ} \mathrm{C}$, por um período de 14 dias. Posteriormente, foram colocadas 200 sementes de soja em cada placa, em contato com o micélio, tendose realizado a incubação em $\mathrm{BOD}$, a $20^{\circ} \mathrm{C}$, por um período de 48 horas, sob escuro contínuo. As sementes foram retiradas, secadas em temperatura ambiente e misturadas a sementes sadias, tendo-se obtido cinco amostras de 400 sementes com percentuais de incidência de: $0 \%, 0,25 \%$ (1/400), 0,50\% (2/400), $0,75 \%(3 / 400)$ e $1 \%(4 / 400)$ de $S$. sclerotiorum na amostra de sementes.

Para a obtenção de amostras de sementes naturalmente contaminadas, oriundas de áreas infestadas pelo patógeno S. sclerotiorum, utilizou-se, como critério, a incidência da doença determinada no campo. Escolheram-se seis amostras de sementes de diferentes cultivares de soja com incidência monitorada da doença, em área de cultivo da região de Arapoti, PR (2406' $15^{\prime \prime}$ S e $\left.49^{\circ} 47^{\prime} 26^{\prime \prime} \mathrm{W}\right)$, durante a safra 2009/2010. No momento da colheita, plantas das duas linhas centrais das parcelas, constituídas por quatro linhas de $20 \mathrm{~m}$, foram coletadas manualmente. Em seguida, as vagens de soja foram debulhadas em batedeira Vencedora B350, (Maquima - Máquinas e Implementos Agrícolas, Cascavel, PR), tendose obtido aproximadamente $10 \mathrm{~kg}$ de sementes por cultivar. As sementes colhidas foram colocadas em sacos de papel do tipo Kraft e enviadas ao laboratório. Posteriormente, com auxílio de calador do tipo simples, coletaram-se subamostras, até a obtenção de uma amostra de trabalho de $500 \mathrm{~g}$ para cada cultivar. Essas amostras foram acondicionadas em sacos de papel do tipo Kraft e armazenadas por quatro meses a $12 \mathrm{e}$ $48 \%$ de umidade relativa do ar, para posterior análise fitopatológica. Foram obtidas seis amostras com as seguintes incidências em campo: 7,23\% (cultivar BRS 295RR); 5,60\% (cultivar FTS Cascavel RR); 3,14\% (cultivar Don Mario 5.8i RR); 2,28\% (cultivar

Pesq. agropec. bras., Brasília, v.47, n.6, p.763-768, jun. 2012 
BRS 255RR); 0,92\% (cultivar BRS 242 RR); e 0,27\% (cultivar NS $4823 \mathrm{RR}$ ).

Para a obtenção de sementes naturalmente contaminadas, colhidas diretamente de plantas doentes, foram marcadas plantas contaminadas por S. sclerotiorum no estádio fenológico R6 (Fehr \& Caviness, 1977), em campos de produção de soja de duas regiões do Estado do Paraná. Para a obtenção das amostras, no momento da colheita, as vagens de soja provenientes de plantas doentes foram colhidas e debulhadas manualmente. As amostras foram homogenizadas e acondicionadas em sacos de papel do tipo Kraft e armazenadas por cinco meses a $12^{\circ} \mathrm{C}$, com $48 \%$ de umidade relativa do ar, para posterior análise fitossanitária das sementes. Foram obtidas cinco amostras de sementes naturalmente infectadas das regiões de: Arapoti (safra 2009/2010), com as cultivares Don Mario 5.8i RR (talhão A), Don Mario 5.8i RR (talhão B) e Spring RR (NK 7054 RR); e Pinhão (safra 2010/2011), com as cultivares Nidera A 4725RG e Don Mario 5.8i RR. Essas amostras de sementes foram consideradas com $100 \%$ de incidência.

Para o teste de sanidade em papel de filtro, foram utilizadas caixas de plástico $(11,0 \times 11,0 \times 3,5 \mathrm{~cm})$ previamente higienizadas com hipoclorito de sódio a 5\%, contendo, como substrato, duas folhas de papel de filtro $80 \mathrm{~g} \mathrm{~m}^{-2}(10 \times 10 \mathrm{~cm})$, esterilizado em autoclave a $1,0 \mathrm{~atm}\left(120^{\circ} \mathrm{C}\right)$, por $20 \mathrm{~min}$. Em seguida, foi adicionada água destilada e esterilizada na proporção 2,5 vezes a massa do papel, sobre o qual foram dispostas sementes escolhidas aleatoriamente, no formato $5 \times 4$, com 20 sementes por caixa, o que totalizou 400 sementes por amostra. Posteriormente, as caixas foram incubadas durante 30 dias em escuro contínuo. As avaliações foram realizadas a cada seis dias, por meio da observação visual da formação de escleródios na semente, para determinação do número de sementes contaminadas na amostra de 400 sementes. $\mathrm{O}$ método foi desenvolvido em três temperaturas de incubação: 7,14 e $20^{\circ} \mathrm{C}$, que foram consideradas como três métodos.

Para a avaliação da incidência de mofo-branco pelo método do rolo de papel Germitest, (JProlab, Curitiba, PR), utilizou-se papel com dimensão $28,0 \times 37,5 \mathrm{~cm}$, previamente esterilizado em autoclave $1,0 \mathrm{~atm}\left(120^{\circ} \mathrm{C}\right)$, por $20 \mathrm{~min}$. Em seguida, foi adicionada água destilada e esterilizada na proporção de 2,5 vezes a massa do papel. Cada rolo foi constituído de três folhas de papel de germinação: duas sob e uma sobre as sementes. Realizou-se exame laboratorial de 400 sementes, distribuídas em oito rolos com 50 sementes cada um, incubadas em germinador a $20^{\circ} \mathrm{C}$, por um período de 14 dias, sob condições de $100 \%$ de umidade relativa, em regime de escuro contínuo. As avaliações foram realizadas por meio da observação visual da formação de escleródios na semente, para determinação do número de sementes contaminadas nas 400 sementes analisadas.

Para a avaliação das sementes pelo método do meio agar-bromofenol Neon S, utilizou-se meio de cultura com a seguinte composição: $39 \mathrm{~g}$ de BDA, $50 \mathrm{mg}$ de azul de bromofenol, $50 \mathrm{mg}$ de cloranfenicol e $50 \mathrm{mg}$ de ácido 2,4-diclorofenoxiacético (2,4-D), em 1,0 L de água destilada. Posteriormente, o meio foi autoclavado a $1,0 \mathrm{~atm}\left(120^{\circ} \mathrm{C}\right)$ por $20 \mathrm{~min}$, tendo-se obtido meio de coloração azul, que foi vertido em placas de Petri (90 mm). Em seguida, foram tomadas, aleatoriamente, dez sementes da amostra analisada, colocadas em placa com o meio Neon-S, o que totalizou 40 placas e 400 sementes. As placas foram, então, incubadas a $20^{\circ} \mathrm{C}$ no escuro, e as leituras foram realizadas de cinco a oito dias após a incubação. Para determinação do número de sementes contaminadas na amostra de 400 sementes, avaliaram-se as que apresentaram formação de micélio característico e de halo amarelo em torno da semente.

A sensibilidade dos métodos, ou sua capacidade em detectar o patógeno presente na amostra, foi determinada pela precisão em quantificar o número de sementes contaminadas nas amostras de 400 sementes analisadas. Foi realizada, também, a análise da repetibilidade para as amostras de sementes artificialmente contaminadas e provenientes de áreas infestadas, a qual é considerada um dos critérios de validação dos testes de patologia de sementes (International Seed Testing Association, 2007). Desse modo, cada método foi repetido quatro vezes por amostra analisada, para determinar se os dados obtidos entre as repetições do mesmo método eram semelhantes.

O modelo experimental utilizado para avaliação da sensibilidade e da repetibilidade dos métodos consistiu de cinco tratamentos e quatro repetições para cada incidência. Os dados obtidos foram submetidos ao teste de aderência e do qui-quadrado $\left(\chi^{2}\right)$, com uso do programa Statistica 8.0 (StatSoft, 2010). 


\section{Resultados e Discussão}

Observou-se sensibilidade dos testes para detecção do patógeno em amostras de sementes de soja inoculadas artificialmente, uma vez que houve relação entre a percentagem da incidência na amostra e a detectada na semente, independentemente do método utilizado (Tabela 1). Além disso, à medida que se aumentou a incidência da amostra, verificou-se acréscimo no número de sementes detectadas com S. sclerotiorum. Esses resultados estão de acordo com os obtidos na literatura, em que a inoculação artificial da semente foi utilizada para avaliar a sensibilidade do método em detectar o fungo (Peres et al., 2002; Napoleão et al., 2006). Ao se analisar a repetibilidade (variação

Tabela 1. Número de sementes contaminadas detectadas por cada método em amostras de 400 sementes, de acordo com os níveis de incidência $(0,0,25,0,5,0,75$ e $1 \%)$ de Sclerotinia sclerotiorum ocasionados por inoculação artificial, em quatro replicatas ${ }^{(1)}$.

\begin{tabular}{|c|c|c|c|c|c|c|c|c|c|c|c|c|c|c|c|c|c|c|c|}
\hline \multirow[t]{2}{*}{ Método } & \multicolumn{4}{|c|}{$0 \%$} & \multicolumn{4}{|c|}{$0,25 \%$} & \multicolumn{4}{|c|}{$0,50 \%$} & \multicolumn{4}{|c|}{$0,75 \%$} & \multicolumn{3}{|c|}{$1 \%$} \\
\hline & 1 & & 3 & 4 & 1 & 2 & 3 & 4 & 1 & 2 & 3 & 4 & 1 & 2 & 3 & 4 & 1 & & 34 \\
\hline \multicolumn{20}{|c|}{ Papel de filtro } \\
\hline $7^{\circ} \mathrm{C}$ & 0 & & 0 & 0 & 1 & 1 & 1 & 1 & 2 & 2 & 2 & 2 & 3 & 3 & 3 & 3 & 4 & & 44 \\
\hline $14^{\circ} \mathrm{C}$ & 0 & 0 & 0 & 0 & 1 & 1 & 1 & 1 & 2 & 2 & 2 & 2 & 3 & 3 & 3 & 3 & 4 & & 44 \\
\hline $20^{\circ} \mathrm{C}$ & 0 & 0 & 0 & 0 & 1 & 1 & 1 & 1 & 2 & 2 & 2 & 2 & 3 & 3 & 3 & 3 & 4 & & 44 \\
\hline \multicolumn{20}{|c|}{ Rolo de papel } \\
\hline $20^{\circ} \mathrm{C}$ & 0 & 0 & 0 & 0 & 1 & 1 & 1 & 1 & 2 & 2 & 2 & 2 & 3 & 3 & 3 & 3 & 4 & & 4 \\
\hline \multicolumn{20}{|l|}{ Neon-S } \\
\hline- & 0 & & 0 & 0 & 1 & 1 & 1 & 1 & 2 & 2 & 2 & 2 & 3 & 3 & 3 & 3 & & & \\
\hline
\end{tabular}

${ }^{(1)}$ Teste de aderência, GL $76 ; \chi^{2} \mathrm{c}=97,55 ; \chi^{2} \mathrm{o}=0,00 ; \mathrm{p}=1,000$. observada em quatro replicatas) dos resultados (Tabela 1), observou-se que os métodos foram eficientes na detecção do fungo $S$. sclerotiorum em sementes contaminadas artificialmente. Segundo a Associação Internacional de Análise de Sementes (International Seed Testing Association, 2007), responsável pela validação dos testes de sementes, a repetibilidade é um dos fatores importantes na aprovação de um procedimento, pois indica se o método apresenta variação tolerável em suas repetições.

A eficiência dos métodos na detecção de $S$. sclerotiorum, em amostras com inoculação artificial, pode ser atribuída ao fato de o patógeno apresentar maior potencial de infecção com esse tipo de inoculação, o que teria facilitado o seu desenvolvimento nas condições de incubação utilizadas nos testes de sanidade, pois o fungo depende somente do ambiente favorável para se desenvolver (Sousa et al., 2008).

Os métodos não diferiram significativamente quanto à capacidade de detectar $S$. sclerotiorum em sementes provenientes de áreas no campo com incidência conhecida da doença (Tabela 2). Não houve relação entre a incidência do fungo no campo e a sua detecção na semente, como observado na amostra da cultivar BRS 295RR, a qual apresentava o maior nível de incidência no campo $(7,23 \%)$, e ainda assim não propiciou a detecção do patógeno na semente. Portanto, os métodos não foram capazes de detectar eficientemente o patógeno em sementes de soja naturalmente infectadas, não tendo evidenciado a variação na incidência da doença no campo.

Tabela 2. Número de sementes contaminadas detectadas por cada método em amostras de 400 sementes, de acordo com os níveis de incidência $(0,27,0,97,2,28,3,14,5,60$ e 7,23\%) de Sclerotinia sclerotiorum em áreas com monitoramento da incidência da doença no campo, em quatro replicatas ${ }^{(3)}$.

\begin{tabular}{|c|c|c|c|c|c|c|c|c|c|c|c|c|c|c|c|c|c|c|c|c|c|c|c|c|}
\hline \multirow[t]{3}{*}{ Método } & \multicolumn{24}{|c|}{ Incidência de $S$. sclerotiorum no campo } \\
\hline & \multicolumn{4}{|c|}{$0,27 \%$} & \multicolumn{4}{|c|}{$0,97 \%$} & \multicolumn{4}{|c|}{$2,28 \%$} & \multicolumn{4}{|c|}{$3,14 \%$} & \multicolumn{4}{|c|}{$5,60 \%$} & \multicolumn{4}{|c|}{$7,23 \%$} \\
\hline & 1 & 2 & 3 & 4 & 1 & 2 & 3 & 4 & 1 & 2 & 3 & 4 & 1 & 2 & 3 & 4 & 1 & 2 & 3 & 4 & 1 & 2 & 3 & 4 \\
\hline \multicolumn{25}{|c|}{ Papel de filtro } \\
\hline $7^{\circ} \mathrm{C}$ & 12 & 1 & 0 & 2 & 0 & 0 & 0 & 0 & 0 & 0 & 0 & 0 & 0 & 0 & 0 & 0 & 0 & 0 & 0 & 0 & 0 & 0 & 0 & 0 \\
\hline $14^{\circ} \mathrm{C}$ & 0 & 0 & 0 & 0 & 0 & 0 & 0 & 0 & 0 & 0 & 0 & 0 & 0 & 0 & 0 & 0 & 0 & 0 & 0 & 0 & 0 & 0 & 0 & 0 \\
\hline $20^{\circ} \mathrm{C}$ & 0 & 0 & 0 & 0 & 0 & 0 & 0 & 0 & 0 & 0 & 0 & 0 & 0 & 0 & 0 & 0 & 0 & 0 & 0 & 3 & 0 & 0 & 0 & 0 \\
\hline \multicolumn{25}{|c|}{ Rolo de papel } \\
\hline $20^{\circ} \mathrm{C}$ & 0 & 0 & 0 & 0 & 0 & 0 & 0 & 0 & 0 & 0 & 0 & 0 & 0 & 4 & 0 & 0 & 0 & 0 & 0 & 0 & 0 & 0 & 0 & 0 \\
\hline \multicolumn{25}{|l|}{ Neon-S } \\
\hline - & 0 & 0 & 0 & 1 & 0 & 0 & 0 & 0 & 0 & 0 & 0 & 0 & 0 & 0 & 0 & 0 & 0 & 0 & 0 & 0 & 0 & 0 & 0 & 0 \\
\hline
\end{tabular}

${ }^{(1)}$ Teste do qui-quadrado, GL $95 ; \chi^{2} \mathrm{c}=118,75 ; \chi^{2} \mathrm{o}=0,00 ; \mathrm{p}=1,000$. 
Neste caso, os métodos apresentaram baixa repetibilidade, já que, quando detectaram a presença do patógeno, isso ocorreu em somente uma das repetições. Ns métodos papel de filtro ("blotter test") a $7^{\circ} \mathrm{C}$ e Neon-S, observou-se incidência similar à apresentada no campo em uma das repetições, mas esta semelhança não foi observada nas demais.

Em amostras de sementes de soja colhidas diretamente de plantas doentes, observou-se que, nas amostras da cultivar Don Mario 5.8i RR (talhão A, região de Arapoti) e Don Mario 5.8i RR (região de Pinhão), houve diferença significativa entre os métodos de detecção (Tabela 3). Os métodos papel de filtro ("blotter test") a $20^{\circ} \mathrm{C}$ (safra 2009/2010) e a $7^{\circ} \mathrm{C}$ (safra 2010/2011) detectaram a maior incidência do patógeno $S$. sclerotiorum. Ao se analisar os dados obtidos com as outras cultivares, verificou-se que não houve consistência para considerar estes métodos mais sensíveis. Cabe ressaltar que as sementes provenientes de plantas da cultivar A 4725RG, com mofo-branco, não apresentaram a presença do patógeno.

Foi observada diferença na sensibilidade dos testes de acordo com a cultivar avaliada. No entanto, não foram encontrados dados na literatura sobre a suscetibilidade das cultivares da soja em estudo, para relacioná-los à detecção na semente. A hipótese de que o ciclo da cultivar poderia influenciar a detecção da incidência do patógeno na semente, em razão do maior período de floração, não pôde ser comprovada, uma vez que a cultivar A 4725RG tem ciclo superprecoce, semelhantemente à Don Mario

Tabela 3. Número de sementes contaminadas por Sclerotinia sclerotiorum, detectadas por cada método em amostras de 400 sementes, colhidas diretamente de plantas doentes em diferentes cultivares de soja ${ }^{(1)}$

\begin{tabular}{|c|c|c|c|c|c|}
\hline \multirow[t]{3}{*}{ Método } & \multicolumn{3}{|c|}{ Arapoti, PR (2009/2010) } & \multicolumn{2}{|c|}{ Pinhão, PR (2010/2011) } \\
\hline & \multicolumn{2}{|c|}{ Don Mario } & \multirow[t]{2}{*}{ Spring RR } & \multirow[t]{2}{*}{ Don Mario } & \multirow[t]{2}{*}{ A $4725 \mathrm{RG}$} \\
\hline & Talhão A & Talhão B & & & \\
\hline \multicolumn{6}{|c|}{ Papel de filtro } \\
\hline $7^{\circ} \mathrm{C}$ & 0 & 0 & 0 & 108 & 0 \\
\hline $14^{\circ} \mathrm{C}$ & 116 & 64 & 24 & 44 & 0 \\
\hline $20^{\circ} \mathrm{C}$ & 200 & 44 & 0 & 40 & 0 \\
\hline \multicolumn{6}{|c|}{ Rolo de papel } \\
\hline $20^{\circ} \mathrm{C}$ & 12 & 8 & 36 & 1 & 0 \\
\hline \multicolumn{6}{|l|}{ Neon-S } \\
\hline - & 0 & 0 & 0 & 0 & 0 \\
\hline
\end{tabular}

${ }^{(1)}$ Teste do qui-quadrado, GL $9 ; \chi^{2} \mathrm{c}=26,29 ; \chi^{2} \mathrm{o}=599,65 ; \mathrm{p}=0,0001$. 5,8i RR (Desempenho de cultivares de soja indicadas para o Rio Grande do Sul, 2011); entretanto, somente nesta última cultivar foi detectada a presença do patógeno nas sementes.

O teste do meio Neon-S não detectou a presença de S. sclerotiorum em sementes provenientes de plantas doentes em nenhuma das cultivares (Tabela 3). Esse resultado, no entanto, pode ter sido prejudicado pela presença de contaminantes, como os fungos Rhizopus sp., Fusarium spp., Penicillum spp. e Aspergillus spp., que possivelmente ocultaram a ocorrência de $S$. sclerotiorum.

Assim, a detecção de S. sclerotiorum em amostras de sementes de soja depende, entre outros fatores, do nível de infecção da semente pelo patógeno. Em sementes com maior potencial de inóculo (inoculadas artificialmente), os métodos apresentaram sensibilidade de detecção do patógeno e repetibilidade dos dados. Contudo, em sementes provenientes de plantas doentes, os métodos não detectaram de forma consistente a presença do patógeno. A semente pode estar infectada naturalmente pelo patógeno, mas apresentar baixo nível de infecção, o que dificultaria a detecção pelos métodos e faria com que esses não expressassem, portanto, a realidade do campo.

Ao se considerar que uma semente pode formar mais de um escleródio, os quais podem permanecer viáveis no solo por mais de 11 anos ou germinar e infestar uma área de produção de sementes (Bolton et al., 2006), ainda são necessárias pesquisas sobre a relação entre o potencial de transmissão de S. sclerotiorum da planta-mãe para as sementes e sobre a sensibilidade dos métodos em detectar a ocorrência da doença, para que estes possam ser utilizados como parâmetro na tomada de decisão quanto ao controle do mofo-branco.

\section{Conclusões}

1. Os métodos avaliados não são eficientes em detectar o patógeno Sclerotinia sclerotiorum em sementes de soja naturalmente contaminadas.

2. Não há relação entre a incidência do patógeno S. sclerotiorum no campo e a incidência verificada nas sementes de soja colhidas.

3. Os níveis de incidência do patógeno em sementes de soja interferem na sensibilidade dos métodos de deteç̧ão. 


\section{Agradecimentos}

Ao Conselho Nacional de Desenvolvimento Científico e Tecnológico e ao Ministério da Agricultura, Pecuária e Abastecimento, pelo apoio financeiro; e ao professor Dr. Aguinaldo José Nascimento, pelo auxílio nas análises estatísticas.

\section{Referências}

BOLTON, M.D.; THOMMA, B.P.H.J.; NELSON, B.D. Sclerotinia sclerotiorum (Lib.) de Bary: biology and molecular traits of a cosmopolitan pathogen. Molecular Plant Pathology, v.7, p.1-16, 2006.

DESEMPENHO de cultivares de soja indicadas para o Rio Grande do Sul: resultado de 2010-2011. Passo Fundo: Fundação Prósementes, 2011. 54p.

FEHR, W.R.; CAVINESS, C.E. Stages of soybean development. Ames: Iowa State University, 1977. 12p. (Special report, 80).

GOMES, D.P.; CAMPOS LEITE, R.M.V.B.; MORAES, M.F.H.; KRONKA, A.Z. Sanidade de sementes de girassol provenientes de três municípios do Estado do Maranhão. Revista Caatinga, v.21, p.55-63, 2008.

HENNEBERG, L; JACCOUD FILHO, D. de S.; RUARO, L.; PANOBIANCO, M. Efficiency of methods to detect Sclerotinia sclerotiorum in commercial soybean seed lots. Revista Brasileira de Sementes, v.34, p.61-69, 2012.

INTERNATIONAL SEED TESTING ASSOCIATION. ISTA method validation for seed testing. Bassersdorf: ISTA, 2007. $70 \mathrm{p}$.

KOCH, E.F. de A. Detecção, incidência e efeitos de Sclerotinia sclerotiorum em sementes de feijão (Phaseolus vulgaris L.). 1998. 59p. Dissertação (Mestrado) - Escola Superior de Agricultura Luiz de Queiroz, Piracicaba.
MACHADO, J.C.; LANGERAK, C.J.; JACCOUD-FILHO, D.S. Seed-borne fungi: a contribution to routine seed health analysis. Bassersdorf: International Seed Testing Association, 2002. 138p.

MANUAL de análise sanitária de sementes. Brasília: Ministério da Agricultura e Reforma Agrária, 2009. 200p.

NAPOLEÃO, R.; NASSER, L.; LOPES, C.; CAFÉ FILHO, A. Neon-S, novo meio para detecção de Sclerotinia sclerotiorum em sementes. Summa Phytopathologica, v.32, p.180-182, 2006.

NASSER, L.C.B.; ARANCIBIA, R.C.; NAPOLEÃO, R. Uso do meio Neon modificado para determinação de Sclerotinia sclerotiorum em sementes de feijão produzidas em áreas irrigadas do cerrado. Fitopatologia Brasileira, v.24, p.309, 1999.

PERES, Â.P.; NASSER, L.C.B.; MACHADO, J. da C. Use of semiseletive media for detection of Sclerotinia sclerotiorum on bean and soybean seeds. Fitopatologia Brasileira, v.27, p.123-127, 2002.

SAHARAN, G.S.; MEHTA, N. Economic importance. In: SAHARAN, G.S.; MEHTA, N. Sclerotinia diseases of crop plants: biology, ecology and disease management. Hisar: Springer, 2007. p.41-45.

SILVA, G.C.; GOMES, D.P.; KRONKA, A.Z.; MORAES, M.H. Qualidade fisiológica e sanitária de sementes de feijoeiro (Phaseolus vulgaris L.) provenientes do Estado de Goiás. Semina: Ciências Agrárias, v.29, p.29-34, 2008.

SOUSA, M.V.; MACHADO, J.C.; PFENNING, L.H.; KAWASAKI, V.H.; ARAÚJO, D.V.; SILVA, A.A.; MARTINI NETO, A. Métodos de inoculação e efeitos de Fusarium oxysporum f. sp. vasinfectum em sementes de algodoeiro. Tropical Plant Pathology, v.33, p.41-48, 2008.

STATSOFT. Statistica: data analysis software system. Version 8.0. Tulsa: StatSoft, 2010.

TAYLOR, E.; BATES, J.; JACCOUD, D. Diagnosis of seedborne pathogen. In: BASRA, A.S. (Ed.). Handbook of seed science and technology. Binghamton: Food Product, 2006. p.649-675.

YANG, X.B.; WORKENEH, F.; LUNDEEN, P. First report of sclerotium production by Sclerotinia sclerotiorum in soil on infected soybean seeds. Plant Disease, v.82, p.264, 1998.

Recebido em 1ำ de fevereiro de 2012 e aprovado em 31 de maio de 2012

Pesq. agropec. bras., Brasília, v.47, n.6, p.763-768, jun. 2012 